\title{
"A SOCIEDADE BRASILEIRA NOS FEZ POBRES": ASSISTÊNCIA SOCIAL E AUTONOMIA ÉTNICA DOS POVOS INDÍGENAS. O CASO DE DOURADOS, MATO GROSSO DO SUL
}

\author{
Júlio César Borges* \\ Ministério do Desenvolvimento Social e Combate à Fome - Brasil
}

Resumo: $O$ artigo pretende analisar a relação dos povos indigenas com a política pública de assistência social (AS) no Brasil. Com base em dados coletados durante trabalho de campo realizado, no ano de 2014, será analisado o caso da Reserva Indigena de Dourados, Mato Grosso do Sul. Na primeira parte, caracterizo a relação desigual da sociedade e Estado nacionais com os povos indigenas para, em seguida, abordar a política de assistência social como oportunidade estatal de enfrentamento da violação de direitos decorrente do cerco colonial. Em seguida, veremos o caso de Dourados como ilustração dos dilemas e possibilidades da autonomia e protagonismo indígena frente a essa política pública. Espera-se contribuir com a discussão em torno da estatalidade apontando casos concretos em que a implementação local da política de AS é permeável, em maior ou menor medida, às demandas dos povos indígenas por adequação às suas organizações sociais e visões de mundo.

Palavras-chave: assistência social, autonomia étnica, políticas públicas, povos indigenas.

Abstract: The article analyzes the relationship of Indigenous Peoples with the public policy of Social Assistance (AS) in Brazil. Based on data collected during field work carried out in 2014, will analyze the case of the Indigenous Reserve of Dourados, Mato Grosso do Sul. In the first part, I characterize the unequal relationship between society and national state with Indigenous Peoples to, then approach the Welfare State politics as an opportunity to face the violation of rights resulting from the colonial siege. Then we will see if Dourados to illustrate the dilemmas and possibilities of autonomy and indigenous role faced with this public policy. It is expected to contribute

* Consultor. Contato: jcborges1977@gmail.com

Horizontes Antropológicos, Porto Alegre, ano 22, n. 46, p. 303-328, jul./dez. 2016 http://dx.doi.org/10.1590/S0104-71832016000200011 
to the discussion of statehood pointing concrete cases where the local implementation of AS policy is permeable to a greater or lesser extent, the demands of Indigenous Peoples by adaptation to their social organizations and worldviews.

Keywords: ethnic autonomy, indigenous peoples, public policy, Social Assistance.

\section{Introduç̃o}

O presente artigo apresenta e discute um caso concreto de política pública direcionada a indígenas. ${ }^{1}$ Trata-se da Proteção Social Básica (PSB), que ganha concretude através da oferta de serviços e programas pelos Centros de Referência em Assistência Social (CRAS). Os CRAS são unidades públicas estatais descentralizadas da política de assistência social (AS), cujo objetivo é prevenir a ocorrência de situações de vulnerabilidades e riscos sociais nos territórios, por meio do desenvolvimento de potencialidades, do fortalecimento de vínculos familiares e comunitários e da ampliação do acesso a direitos de cidadania. O principal serviço é o Serviço de Proteção e Atendimento Integral à Família (PAIF).

O caso etnográfico aqui analisado é o dos indígenas (na maioria, Guarani Kaiowá e Terena) da cidade de Dourados, Mato Grosso do Sul, visitados durante trabalho de campo realizado, entre julho e agosto de 2014, em mais sete municípios brasileiros, das cinco grandes regiões do País. ${ }^{2}$ Dourados foi escolhida porque ilustra bem como os conceitos de "vulnerabilidade" e "risco social" estão relacionados a situações concretas decorrentes de fatores históricos e sociopolíticos: a violência dos conflitos fundiários, vivência de discriminação

\footnotetext{
Ele é baseado num dos relatórios, por mim elaborados, no âmbito do contrato de consultoria firmado com o Ministério do Desenvolvimento Social e Combate à Fome (MDS), por intermédio do Programa das Nações Unidas para o Desenvolvimento (PNUD), e cujo produto final é uma proposta de publicação com orientações técnicas para os profissionais que atuam, nos CRAS, junto a essa parcela da população brasileira.

2 As cidades selecionadas foram São Paulo, Porto Alegre, Dourados (MS), Caarapó (MS), Manaus, São Gabriel da Cachoeira (AM), Porto Seguro (BA) e Prado (BA). Dentre os critérios que pautaram essa escolha, destacam-se: diferenças de portes populacionais e de amadurecimento do diálogo político entre o poder público local e os coletivos indígenas; oportunidade de coleta primária de dados sobre a oferta de serviços socioassistenciais para indígenas que vivem em contexto urbano de metrópoles situadas nas regiões Norte, Sul e Sudeste; a produção de conhecimento sobre o trabalho social de dois CRAS voltados exclusivamente para indígenas, um deles justamente o de Dourados. Para mais informações, ver Borges (2015).
}

Horizontes Antropológicos, Porto Alegre, ano 22, n. 46, p. 303-328, jul./dez. 2016 
étnica, ausência de serviços e políticas públicas em seus territórios, fraca ou nula capacidade de produção da vida material de forma autônoma e de acordo com seus modos de vida, dentre outras. Mostra a pertinência de um olhar específico que reconheça a história de exclusão e violência a que foram submetidos os povos indígenas, sem deixar de considerar sua condição de sujeitos na definição dos eixos de atuação dos serviços socioassistenciais - nosso foco aqui. ${ }^{3}$

Seu ponto de partida teórico é o seguinte. Muitas das vulnerabilidades que afetam famílias e coletivos indígenas advêm do relacionamento desigual, por vezes violento, que as frentes de expansão econômica - primeiramente europeia e depois brasileiras - lhes impuseram desde o século XVI até os dias atuais. Os dados coletados in loco ilustram criticamente as circunstâncias históricas atuais que fazem com que, hoje em dia, os povos indígenas demandem serviços, programas, projetos e benefícios da assistência social. O que sobressai e deve ser enfrentado, como veremos, é a persistência de padrões coloniais de poder, que perpassam o aparato estatal e insistem em excluir os grupos sociais nativos a partir da definição preconceituosa do que são os "índios".

O objetivo final do artigo é demonstrar limites e possibilidades concernentes ao protagonismo indígena na estatalidade da assistência social. Sua ênfase é na dimensão operativa da política pública, ou seja, o processo de implementação já em curso, em que se põem em marcha serviços, programas e projetos governamentais. Veremos, pois, a agencialidade indígena na resistência étnico-cultural frente ao cerco colonial e a autonomia étnica em curso na construção prática dessa política pública.

\section{Estado nacional e o cerco colonial dos povos indígenas no Brasil}

A expressão "povos indígenas" é utilizada para se referir a uma multiplicidade de grupos sociais nativos. Trata-se de populações remanescentes

\footnotetext{
Em campo, foram realizadas entrevistas com gestores/as e equipes técnicas dos CRAS (psicólogas e assistentes sociais), famílias e lideranças indígenas, além da observação do espaço físico das unidades e atividades desenvolvidas com usuários/as e registros fotográficos. As entrevistas foram gravadas - mediante autorização prévia formal dos sujeitos - seguindo roteiros semiestruturados para cada categoria de sujeito, além de caderno de campo e máquina fotográfica para o registro de dados diretos oriundos de conversas informais e da observação direta de cenas presenciadas nos CRAS. Também reuni documentos (relatórios administrativos, estudos técnicos, memórias de reunião, etc.) sobre a política de assistência social e a atuação dos CRAS selecionados em todos os municípios, a exemplo de Dourados.
}

Horizontes Antropológicos, Porto Alegre, ano 22, n. 46, p. 303-328, jul./dez. 2016 
daquelas que aqui viviam quando da chegada dos europeus, no final do século $\mathrm{XV} .{ }^{4} \mathrm{~A}$ história do relacionamento dessas sociedades originárias com o Estado nacional - construído, após a invasão europeia, sobre seus territórios outrora "autóctones" - é indissociável da expansão do sistema capitalista, sendo marcada por capítulos de apresamento, expulsão, deslocamentos forçados, assimilação cultural e extermínio físico. As atividades econômicas ligadas aos movimentos de expansão da fronteira nacional corresponderam, necessariamente, à diminuição da população e de territórios indígenas. Grosso modo, o contato dos colonos com os indígenas teve três grandes interesses ao longo dos séculos, concomitantes em alguns períodos. Entre a invasão ibérica e o final do século XVII, interessava principalmente a mão de obra indígena; entre os séculos XVIII e XIX, a ocupação das suas terras para instalação de fazendas e extração de minérios passou a ser o foco das ações indigenistas; no século XX e princípio do XXI, se intensificou o esbulho dos solos e subsolos dos territórios indígenas, cuja biodiversidade e conhecimentos tradicionais associados também passaram a interessar ao capital (Carneiro da Cunha, 2012; Gomes, 1991; Ribeiro, 1996; Viveiros de Castro, 1993).

As políticas de Estado - produzidas e negociadas no complexo cultural (e normativo) do capitalismo contemporâneo - demoraram para reconhecer a cidadania indígena. Antes o contrário: vêm refletindo noções e crenças hegemônicas que sustentam formas de etnocentrismo, que atravessam as instâncias federativas formais e conformam práticas capilares de governabilidade, que sistematicamente vêm excluindo os índios dos processos de estatização no Brasil, conforme assinala Lima (1995; ver também Foucault, 2002, cap. 2-3; Marston, 2004). Nas últimas décadas, os índios tiveram razoável sucesso na resistência ao status de ser transitório e, logo, no reconhecimento de que a eles poderiam (deveriam) ser direcionados os mesmos programas, projetos

4 A utilização da expressão "povos indígenas" também tem justificativa política. Ela está presente em vários tratados jurídicos internacionais dos quais o Brasil faz parte - a exemplo da Declaração dos Direitos Humanos de Viena, a Convenção sobre Proteção e Promoção da Diversidade das Expressões Culturais, a Convenção $n^{\circ} 169$ da Organização Internacional do Trabalho (OIT, 1989) e a Declaração das Nações Unidas sobre Direitos dos Povos Indígenas (Nações Unidas, 2008). Ressalta-se que, ao contrário do que alguns consideram, a palavra "povo" não se presta a pretensões separatistas de indígenas dispostos a constituir novos países pela apartação de parte do território nacional. Ademais, o presente artigo acompanha a subprocuradora-geral da República, Dra. Ela Wiecko Castilho (2009, p. 22), segundo a qual "dizer que uma determinada população constitui um povo indígena ressalta a especificidade cultural e assegura o olhar diferenciado das políticas públicas para aquele grupo".

Horizontes Antropológicos, Porto Alegre, ano 22, n. 46, p. 303-328, jul./dez. 2016 
e ações concebidos para a população em geral. Somente no final da década de 1980, é que os índios foram plenamente reconhecidos como sujeitos de direitos territoriais, civis e políticos, não sem uma tenaz resistência frente ao padrão colonial de poder vigente (Ramos, 1998; Quijano, 2014).

O movimento indígena organizado foi o responsável pelo reconhecimento dessa alteridade radical pelo Estado nacional brasileiro. Sua presença na cena política das últimas décadas é a expressão contestatória de sociedades etnicamente diversificadas que não mais aceitam a homogeneização imposta por programas governamentais que, inspirados no liberalismo ocidental, insistem em negar o pluralismo cultural. A consequência inevitável do pensamento liberal não pluralista é a negação da autodeterminação como atributo político dos povos indígenas. Ao recusar a pluralidade como fundamento do regime democrático, os agentes estatais dão força a iniciativas integracionistas que se expressam numa linguagem legalista e essencializadora, enquanto fazem brilhar os direitos individuais na condição de faróis universais da razão humana (Díaz Polanco, 2005; Ramos, 2001). Para introduzir mudanças no quadro jurídico dessa organização sociopolítica se assume como racional e moralmente legítima (o Estado), os indígenas se insurgiram como sujeitos coletivos cuja ação política, nos anos de 1970 e 1980, foi bem-sucedida na sua "afirmação existencial" pela politização da identidade étnica.

Uma nova noção de cidadania que ressalta a autodeterminação por coletividades, diversidade cultural e pluralismo tem ser reconciliada com a noção antiga de cidadania que se baseia em direitos iguais partilhados por portadores de uma identidade cultural homogênea que era equivalente ao Estado. (Baines, 2001, p. 13-14).

A Constituição Federal de 1988 (CF 1988) impôs uma nova postura do Estado frente aos povos indígenas. Ela inaugurou uma nova era de cidadania porque firmou na legislação nacional o respeito às coletividades indígenas como sujeitos culturalmente diferenciados - sujeitos com direito a terra, educação e seguridade social que respeitem suas diferenças. ${ }^{5}$ Isso no plano jurídico-formal.

5 A aprovação dos direitos indígenas na Constituição Federal foi resultado da mobilização do movimento indígena brasileiro, que ganhou força e respaldo no país devido às suas articulações, no final da década 
Na prática, a defesa dos territórios é, ainda hoje, o principal tópico da luta pelos direitos indígenas em todos os quadrantes do país, sendo mais crítica a situação dos povos indígenas das regiões Sul e Sudeste, provocando mortes (assassinatos e suicídios) especialmente no Mato Grosso do Sul. A garantia da terra se associa ao pleito por desenvolvimento que respeite suas especificidades culturais e territoriais, com políticas diferenciadas de saúde, educação e assistência social. Desde meados da década de 1990, a política de saúde está estruturada num subsistema próprio de atendimento às aldeias indígenas e, com a proteção territorial, conseguiu reverter o quadro de decréscimo populacional do início do século XX. No início dos anos 2000, os povos indígenas passaram a contar com a Convenção $\mathrm{n}^{0} 169$, da Organização Internacional do Trabalho (OIT, 1989), e, desde 2007, com Declaração das Nações Unidas sobre Direitos dos Povos Indígenas (Nações Unidas, 2008), na defesa dos seus direitos, em particular o de serem consultados antes da implementação de políticas e obras que lhes afetem direta ou indiretamente. ${ }^{6}$

Apesar do avanço na legislação, os indígenas ainda enfrentam ameaças e violações de direitos. Obras e mais obras de infraestrutura ainda vêm impactando seus territórios, projetos de lei federal buscaram lhes subtrair as garantias constitucionais e as armas de fazendeiros, madeireiros e mineradores seguem ceifando vidas indígenas.

A colonização poderia ter resultado numa catástrofe demográfica incontornável para os indígenas. De fato, o resultado das guerras se somou às doenças na sua depopulação: de aproximadamente 5 milhões de pessoas, vivendo em mais de 1500 sociedades, restaram cerca de 900 mil indivíduos indígenas distribuídos em 305 etnias no Brasil de hoje (IBGE, 2012). Apesar da

de 1970, com o movimento indígena internacional, com a sociedade civil organizada e com a opinião pública. Sua importância reside em dois aspectos: a) os art. 231 e 232 - que tratam "Dos Índios" -, asseguram o direito à diferença, voz própria e usufruto exclusivo das riquezas do solo, rios e lagos existentes nas terras tradicionalmente ocupadas; b) o art. 232 garante relativa autonomia política ao afirmar que "os índios, suas comunidades e organizações são partes legítimas para ingressar em juízo em defesa de seus direitos e interesses", intervindo o Ministério Público em todos os atos do processo.

6 Acompanhando as mudanças nas perspectivas sobre povos indígenas impulsionadas pelo movimento da sociedade civil organizada, a Convenção $n^{\circ} 169$ substituiu o preceito legal da integração, que constava na Convenção OIT $n^{\circ} 107$, em vigor desde 1957, pelo princípio da autodeterminação, com a prerrogativa da participação livre na "adoção de decisões em instituições efetivas ou organismos administrativos e de outra natureza responsáveis pelas políticas e programas que lhes sejam concernentes” (OIT, 1989, art. $6^{\circ}$ ). Para o campo da seguridade social e, em especial, da assistência social, são particularmente relevantes os art. $7^{\circ}$ e 24 .

Horizontes Antropológicos, Porto Alegre, ano 22, n. 46, p. 303-328, jul./dez. 2016 
dizimação colonial, ainda hoje permanecem operantes modos de vida, formas de organização política, saberes e visões de mundo diversos; resistem povos que souberam defender seus interesses ante a violenta expansão capitalista em nosso país e, hoje, afirmam suas identidades étnicas num contexto jurídico favorável ao reconhecimento dos seus direitos coletivos e à elaboração de políticas públicas diferenciadas.

O propósito deste artigo é justamente compreender como a assistência social vem sendo apropriada pelos indígenas. Frente ao quadro de inúmeros riscos - gerados pelo cerco colonial -, como se comportam índios e gestores públicos frente à construção da estatalidade nesse âmbito da política social brasileira? A estatalidade é, em certas conjunturas, aberta à participação de classes ou grupos subalternos ante o predomínio das elites hegemônicas, mas pressupõe pactos sucessivos e necessários à organização sociopolítica. Como assinala Roca (2005, p. 17, tradução minha), "são acordos de duração variável cujas cláusulas se vão reformulando por vias que, em geral, não são pacíficas. Se produzem conflitos e enfrentamentos em meio a etapas onde alternam a bonança e a escassez, o triunfo e a derrota, o sofrimento e o bem-estar". Tal institucionalidade não se resume a certos aspectos formais, mas antes depende de sentimentos de pertencimento, identificação e compromisso dos sujeitos com seu Estado. Como os indígenas brasileiros participam da "produção da matéria estatal" (Zavaleta Mercado, 2009, p. 327), ou seja, em que medida são parte de sua substância social fazendo nela incidir suas visões de mundo, valores e formas de autoridade e sociabilidade?

Dourados, Mato Grosso do Sul, é o caso etnográfico que nos permitirá visualizar as disputas, alianças, acordos, consensos e desacordos entre distintos atores, cuja interação, ora simétrica, ora desigual, resulta em ações e programas públicos de "proteção social" de pessoas e coletivos indígenas. Antes, vejamos os principais marcos legais da assistência social.

\section{A política pública de assistência social para povos indígenas}

Como vimos, a Constituição Federal de 1988 é um divisor de águas na legislação indigenista brasileira porque eliminou o preceito da tutela e da integração. Ela deu fundamento legal ao combate ao racismo e às diversas formas de preconceito, ao prever que a diversidade étnica do país assume contornos específicos a partir de critérios de autoidentificação de cada grupo. É também 
a base jurídica máxima para afirmação do direito à autodeterminação acionado pelos povos indígenas nas suas iniciativas de autonomia étnica.

A Constituição Federal também inaugurou uma nova etapa histórica para a assistência social, estabelecida como direito de cidadania sob responsabilidade do Estado. Desde então, foi editado um conjunto de normas federais que consolidaram a AS como política pública - gerida pelos três entes federativos com fundos públicos e instâncias de participação e controle social - que, assim, começou a superar "um quadro histórico de quase ausência da ação pública, marcada pelo clientelismo e patrimonialismo, pelos auxílios e doações, pelas iniciativas fragmentadas, voluntaristas e mesmo improvisadas do assistencialismo" (Colin; Jaccoud, 2013, p. 43). Atualmente, a assistência social é uma política pública que busca prover seguranças socioassistenciais à população brasileira e, para tanto, tem como suporte de ações a vigilância socioassistencial: análise territorial da capacidade protetiva das famílias e produção de informações sobre ocorrências de vulnerabilidades, ameaças, vitimizações e danos. As seguranças de sobrevivência (renda e autonomia), acolhida, convívio familiar e comunitário devem ser garantidas mediante a oferta integrada de serviços e benefícios socioassistenciais, com uma visão técnico-profissional que alcance os diferentes fatores geradores de vulnerabilidade. Para tanto, é indispensável uma atuação intersetorial com outras políticas públicas - saúde, educação, segurança alimentar, previdência social, emprego, habitação - e o sistema de Justiça (Colin; Jaccoud, 2013). Se, historicamente, ela tem sido sinônimo de favores políticos e caridade, desde 1988 passou a formar um dos três pilares da seguridade social, ao lado da saúde e da previdência. ${ }^{7}$

\footnotetext{
No âmbito da previdência social, os indígenas acessam a aposentadoria na forma de "segurados especiais", desde que devidamente enquadrados na forma estabelecida pela lei previdenciária (Brasil, 2010b). Para os efeitos práticos da aposentadoria na vida dos indígenas (que também têm direito ao Benefício de Prestação Continuada - BPC), ver os casos etnográficos descritos por Alvarez (2009). Quanto à saúde, o Subsistema de Atenção à Saúde Indígena (SASISUS), gerido pela Secretaria Especial de Atenção à Saúde Indígena do Ministério da Saúde (SESAI/MS), é normatizado segundo os pressupostos constitucionais de acesso universal e integral à saúde. É composto por 34 Distritos Sanitários Especiais Indígenas (DSEI), que são unidades supramunicipais descentralizadas, com autonomia administrativa e responsabilidade sanitária. A normatização da saúde indígena decorre da lei no 8.080/1990 (Brasil, 1990), dos decretos no 3.156/1999 e n ${ }^{\circ}$ 7.336/2010 (Brasil, 1999a, 2010a), da lei no 9836/1999 (Brasil, 1999b), da Política Nacional de Atenção à Saúde dos Povos Indígenas - portaria do Ministério da Saúde $n^{\circ}$ 254/2002 (Brasil, 2002) - e das portarias do Ministério da Saúde n 2.656/2007 (Brasil, 2007b) - alterada pela portaria $n^{\circ}$ 2.760/2008 (Brasil, 2008) - e no 116/2009 (Brasil, 2009). Ver: Silva (2010), Santos e Coimbra Jr. (2003), Novo (2010), Diehl, Langdon e Dias-Scopel (2012).
}

Horizontes Antropológicos, Porto Alegre, ano 22, n. 46, p. 303-328, jul./dez. 2016 
Do ponto de vista normativo, são sólidas as bases da assistência social como política pública de proteção social. Os marcos legais que acompanham a CF 1988 são a lei no 8.742/1993 (Brasil, 1993) que, ao instituir a Lei Orgânica da Assistência Social (LOAS), regulamentou a AS como política pública; a Política Nacional de Assistência Social (PNAS), aprovada pela Resolução CNAS (Conselho Nacional de Assistência Social) no 145 (Brasil, 2004), de 2004, que estabeleceu os eixos estruturantes para implantação do Sistema Único de Assistência Social (SUAS); a Norma Operacional Básica do SUAS (Brasil, 2005), de 2005, que definiu parâmetros para implantação e operacionalização do sistema em todo o país; a lei no 12.435/2011 (Brasil, 2011), que representou o acolhimento do SUAS no corpo da LOAS; e a nova Norma Operacional Básica que, aprovada pela Resolução CNAS no 33 (Brasil, 2012a), em 12 de dezembro de 2012, substituiu aquela de 2005. Ao lado da identificação das situações sociais objeto de garantias de direito e da definição dos serviços e benefícios ofertados sem prévia contribuição, a política de AS também avançou ao identificar seus usuários. Dentre eles, os "cidadãos e grupos que se encontram em situações de vulnerabilidade e risco", tais como famílias e indivíduos com perda ou fragilidade de vínculos de pertencimento e sociabilidade, identidades estigmatizadas em termos étnicos e culturais, exclusão pela pobreza e pelo precário ou nulo acesso a políticas públicas (PNAS, item 2.4). ${ }^{8}$

Para enfrentar desigualdades socioterritoriais e universalizar direitos, a AS oferece proteção social básica e especial. Esses são os dois níveis em que estão organizados - em rede e de forma integrada - serviços, projetos, programas e benefícios com vistas a garantir convivência familiar e comunitária, com inclusão e equidade dos usuários e grupos específicos (PNAS, item 2.3). ${ }^{9}$ No que concerne à proteção social básica, foco do presente artigo, é nos CRAS que seus serviços são organizados e ofertados, com destaque para o PAIF, considerado a "porta de entrada" para o SUAS. ${ }^{10}$

Em se considerando os povos indígenas, o desafio é dar concretude ao que está previsto em lei. Na esteira dos princípios basilares da PNAS e da NOBSUAS 2005, foi constituído um Grupo de Trabalho (GT) pelo CNAS, mediante

\footnotetext{
Cf. Brasil (2004).

9 Cf. Brasil (2004).

${ }^{10}$ Estima-se a presença dos CRAS em 98\% dos municípios brasileiros.
} 
a resolução $\mathrm{n}^{\circ}$ 47, de 22 de março de 2006 (Brasil, 2006), com objetivo de acompanhar e avaliar a gestão dos recursos, os impactos sociais e o desempenho das ações da Rede de Serviços de Proteção Social Básica nas comunidades indígenas. No relatório conclusivo de suas atividades, o GT considerou que "o adequado atendimento nos serviços operados nestes CRAS [Indígenas], depende de uma melhor qualificação técnica do trabalho e das equipes responsáveis" e asseverou que "a questão da instalação e operação de CRAS assim como de implementação PAIF e de demais serviços de proteção social básica junto à população indígena deve ser objeto de debates, com esforços dirigidos, em especial, a uma melhor definição dos serviços que devam ser ofertados a esta população" (Brasil, 2007a, p. 31). Ocorre que, em 2014, sequer havia uma única cartilha com instruções para as equipes dos CRAS que atuam com famílias indígenas. ${ }^{11}$ Ademais, vale aqui a observação de Sposati (2013, p. 30), de que existe uma "força negativa e de resistência à conquista de igualdade como condição de direito à proteção social pública. [...] Essa resistência é mais presente na instância dos municípios", justamente os entes responsáveis pela administração dos CRAS e pela oferta da proteção social básica.

Além disso, a política ainda carece de maior amadurecimento para o atendimento de grupos populacionais específicos, por exemplo, quando se consideram as formas diferenciadas de organização social e visão de mundo das sociedades indígenas. Isso requer a relativização dos conceitos operacionais da política de AS em face da diversidade de arranjos familiares, sistemas produtivos, divisão sexual do trabalho, valores morais e, de outro lado, a superação da discriminação - por vezes violenta - que os indígenas sofrem nos municípios em que vivem. "Vulnerabilidade", "risco social", "autonomia", "protagonismo", "pobreza", dentre outros conceitos operacionais, têm conotação distinta nas comunidades indígenas em função dos seus modos de vida, dos contextos socioculturais e das situações econômicas (em geral, de caráter colonial) em que estão inseridas, o que ademais impõe limitações à participação indígena na formulação e execução dos serviços. Vejamos o caso de Dourados.

11 Em 2014, 2117 CRAS tinham comunidades tradicionais no seu território de abrangência, sendo que 545 atendiam indígenas e 19 CRAS funcionavam "dentro de uma comunidade indígena", de acordo com os microdados do Censo SUAS 2014, cuja base "Dados Gerais" dos CRAS conta com 8088 unidades (cf. http://aplicacoes.mds.gov.br/sagi/snas/vigilancia/index2.php). 


\section{0 caso do CRAS Indígena de Dourados}

O município de Dourados, estado de Mato Grosso do Sul, tem uma população total de cerca de 200 mil pessoas. A implantação dos CRAS começou em 2007 e, hoje em dia, são oito unidades: CRAS Central, Água Boa, Cachoeirinha, Canaã I, Jóquei Clube, Parque do Lago II, Vila Vargas e o CRAS Indígena Bororó. ${ }^{12} \mathrm{O}$ CRAS Indígena é responsável pela oferta de benefícios e serviços socioassistenciais da PSB a toda população da Terra Indígena (TI) de Dourados. Com 3475 hectares, localizada a cerca de $220 \mathrm{~km}$ de Campo Grande, capital do estado, a TI Dourados somava, em 2010, 11.138 habitantes, sendo a sexta TI mais populosa do país e a primeira dentre aquelas do sul de MS, apesar do seu tamanho diminuto (IBGE, 2012).

O estado do Mato Grosso do Sul, que, até os anos de 1970, fez parte do grande estado do Mato Grosso, deve sua atual expansão econômica à proximidade com os estados do Sul e Sudeste e à fertilidade dos seus solos. Fazendas vêm avançando sobre os territórios indígenas desde o início do século XX, cujo marco histórico é a Colônia Agrícola Nacional de Dourados, que resultou na doação de terras, em módulos de 30 hectares, a famílias nordestinas que se dirigiam a São Paulo e Rio de Janeiro no final dos anos de 1930 devido a uma grande seca. Esse projeto foi implantado no coração do território dos índios guarani, que, sem consulta, já vinham sendo paulatinamente transferidos para pequenas reservas criadas pelo Serviço de Proteção ao Índio (SPI), desde meados da década de 1910. A Terra Indígena de Dourados é uma dessas áreas, de um total de oito, que liberaram o sul do estado para o avanço das empresas agropecuárias. Hoje em dia, nessas oito reservas vivem perto de 2/3 da população guarani, além de outras etnias do MS. Violência, pobreza e doença persistem até os dias de hoje, agravadas pela venda das pequenas propriedades para fazendeiros que impõem à força latifúndios de grãos destinados à exportação. ${ }^{13}$

12 O SUAS foi regulamentado pelo poder público local através da lei municipal $\mathrm{n}^{\circ} 3.783$, de 23 de abril de 2014 (Dourados, 2014). O CRAS Indígena foi inaugurado em 8 de dezembro de 2007, sendo o primeiro do gênero no país. Ver: http://www.dourados.ms.gov.br/index.php/semas-historico/.

13 No caso da TI Dourados, o Ministério Público Federal em Dourados investiga a ocupação de pedaços de terra por fazendeiros, que a reduziram de 3,6 mil hectares originalmente demarcados para 3475 hectares. Ver Pimentel (2014); ver também http://ti.socioambiental.org/pt-br/\#!/pt-br/terras-indigenas/3656.

Horizontes Antropológicos, Porto Alegre, ano 22, n. 46, p. 303-328, jul./dez. 2016 
Criada em 1917, a TI Dourados abriga atualmente três grupos. São os Guarani Kaiowá, com 7730 pessoas; Guarani Nandeva (que se autodenominam apenas "Guarani" no MS), com 563, e Terena, que contabilizam 2726 indivíduos (IBGE, 2012). Há ainda cinco que declararam outras etnias (Guató e Kadiwéu) e mais 114 pessoas que não especificaram pertencimento étnico. Os Terena foram levados para Dourados pelo SPI, que supunha serem eles mais aptos para a agricultura. Muitos dos grupos kaiowá e guarani que lá vivem hoje foram trazidos de lugares muito distintos, e não tinham um histórico de convivência e relação entre eles. Nesse contexto, o trabalho social não pode fazer abstração das reivindicações territoriais baseadas na noção de tekoha. Ou seja, elas apontam para a existência de vínculos precisos entre famílias extensas e lugares específicos nos quais se dão as relações comunitárias e a partir dos quais se estabelecem laços intercomunitários. Em torno da TI Dourados, num raio de $35 \mathrm{~km}$, existem seis acampamentos indígenas: Pakurity, Apykai, Mudas MS/Nhu Porã, Nhu Verá, Boquerón e Paso Piraju. A partir da mobilização de antigos residentes em Dourados, no fim dos anos 1990, foi demarcada a TI Jatayvary, no município de Lima Campo, a cerca de $60 \mathrm{~km}$ dali. Há mais de dez outros grupos hoje residentes dentro da TI Dourados que reivindicam o retorno aos seus tekoha, alguns dos quais já adensando os mais de 30 acampamentos da região - alguns em beira de estrada, outros dentro de fazendas, aguardando identificação de terras ${ }^{14}$ (Pimentel, 2014, p. 5).

A disposição política desses grupos guarani em garantir o direito às terras onde estão e onde outrora estiveram é o pano de fundo em que se movimenta a equipe do CRAS Indígena Bororó. Os relativos avanços na recuperação de antigos espaços territoriais por parte dos índios provocaram reações de empresas agropecuárias e a intensificação de conflitos na disputa por terras. Nos últimos anos, verifica-se a exacerbação da violência contra os índios, com toda sorte de procedimentos que vão de assassinatos, raptos de pessoas indígenas a prisões sem qualquer motivação ou prova de crime, sugerindo que o delito estaria no fato de ser índio. No interior da reserva, se avolumam os casos de alcoolismo, uso de drogas, exploração sexual, violência doméstica e interfamiliar,

14 Os Kaiowá e Guarani estão distribuídos em 30 terras indígenas espalhadas pelo sul de MS, que somam aproximadamente 43 mil hectares. Diante do passivo a ser demarcado, estimado em cerca de $600 \mathrm{mil}$ hectares, existem 90 mil hectares já reconhecidos como terra indígena, porém com processos de demarcação paralisados nas esferas judicial e/ou administrativa. Ver: Pimentel (2014).

Horizontes Antropológicos, Porto Alegre, ano 22, n. 46, p. 303-328, jul./dez. 2016 
negligência com pessoas idosas e deficientes, privação material e insegurança alimentar. As situações de risco, vulnerabilidade social e, mais grave, violação cotidiana de direitos decorrem, em grande parte, do confinamento a que foram forçados os indígenas e dos conflitos fundiários e interétnicos associados.

O CRAS Indígena é responsável pela oferta da PSB às famílias indígenas da TI Dourados. Em sua área de cobertura, estão duas aldeias (Bororó e Jaguapiru) que, juntas, somam cerca de 11 mil pessoas segundo o Censo Indígena 2010, ou mais de 14 mil conforme as estimativas da sua equipe técnica. Diante disso, o primeiro aspecto a ser destacado é a enorme demanda por informações, documentação civil, transferência de renda e benefícios eventuais (como cestas de alimentos e lonas) que não pode ser suprida devido ao reduzido número de funcionários. Isso afeta também os serviços, pois além dos usuários da reserva de Dourados também recorrem ao CRAS famílias dos acampamentos e da TI Panambizinho. Como a demanda é muito grande de famílias com violação de direitos e há déficit de funcionários técnicos em face da procura, a busca ativa é limitada. O CRAS responde, principalmente, à demanda espontânea de famílias residentes ali próximas, no seu entorno; as que moram longe não estão cobertas ou são convidadas (quando ocorre busca ativa) para participar das atividades e não conseguem ir. A oferta dos serviços da proteção básica concorre - não só com a procura por benefícios eventuais - também com atendimento a situações de violação de direitos e rupturas de vínculos sociais. Como estratégia para aliviar a sobrecarrega, a equipe de referência trabalha junto com as lideranças (capitão e sua equipe ${ }^{15}$ ) no aconselhamento das famílias. Esta é uma característica importante do trabalho deste CRAS - a "parceria" com os atores locais (Borges, 2015).

As lideranças tradicionais são chamadas para acompanhar as visitas domiciliares porque estariam mais próximas das famílias. Como conhecem as famílias melhor que o CRAS, quando as equipes técnicas se deslocam na companhia das lideranças são vistas com mais respeito. As lideranças são ouvidas e respeitadas dentro da comunidade, de modo que muitas famílias só procuram o CRAS depois de interpeladas por essas autoridades políticas, tidas como bons conselheiros (conforme tipologia clássica de Clastres, 1990). Essa relação

15 O cargo de "capitão" foi criado pelo SPI nos moldes das organizações militares. Ele veio a representar o líder da comunidade (ou cacique), sendo assessorado pelo vice-capitão e pelos conselheiros. 
começou no início de 2014, com a eleição de Gaudêncio Benitez para a função de "capitão" (cacique) da Bororó; mas ouvi que o capitão da Jaguapiru também está à disposição para dar apoio para alcançar as famílias mais vulneráveis. Gaudêncio, como dito, também tem conhecimento do CRAS porque é seu motorista, o que facilita a logística de deslocamento das equipes até as famílias e a sugestão de encaminhamento para tal ou qual serviço ou benefício. Ou seja, não há qualquer institucionalidade nessa estratégia de ação (Borges, 2015).

A linha do diálogo intercultural é tênue entre o respeito e a interferência indevida. Os profissionais reconhecem a necessidade de capacitação antropológica para lidar com as diferenças étnico-culturais sem imposições arbitrárias. Embora indígenas, os técnicos de referência do CRAS (duas assistentes sociais e uma psicóloga) se queixam de não ter recebido qualquer treinamento, ou assessoria antropológica, para o trabalho social com as famílias da reserva. Com o agravante do limitado quadro de pessoal, isso faz com que o PAIF aí ofertado não tenha recebido qualquer adequação:

Eu acredito que aqui na nossa comunidade deveria ser diferenciado, mas não é. O PAIF que vem da nossa SEMAS [Secretaria Municipal de Assistência Social] é tudo igual; deveria ser diferente a começar pelos funcionários. Tinha de ter capacitação porque são costumes de culturas diferentes. Não é igual lá; aqui é diferente. (E. M, psicóloga, durante entrevista em grupo concedida no dia 23 de julho de 2014).

Eles colocam a limitação, que a Tipificação impõe aos CRAS. Mas nossa demanda como CRAS Indígena é tanta, que não tem como obedecer; se chegar uma família aqui com direitos violados, em situação de extrema pobreza, como vamos deixar de atender? A violação de direitos é tanta, é tanta, que não tem como obedecer. E a cada dia que passa, a procura aumenta porque as outras famílias começam a saber [do trabalho social realizado no CRAS]. (I. M., assistente social, durante a mesma entrevista).

É bastante complexa a realidade social, política e cultural em que o CRAS Indígena Bororó se insere. Álcool e drogas têm fragilizado os indígenas porque a reserva está situada entre duas cidades (Dourados e Itaporã) e as famílias indígenas são facilmente alcançadas por pessoas estranhas à comunidade, que aliciam os menores. A pobreza e extrema pobreza se associam aos ilícitos para geração de casos de violência, que se agravam na região em virtude do confinamento a que os índios foram submetidos nos últimos anos. Famílias de fora 
da reserva também buscam o CRAS, principalmente dos acampamentos onde a situação vivida é de extrema vulnerabilidade social: violências, abuso sexual, falta de documentação civil, insegurança alimentar grave, famílias dormem ao leu, falta de escolas e serviços de saúde, crianças são retiradas das famílias indígenas por instituições exógenas sem consulta prévia (Borges, 2015).

As conversas que tive com as mulheres indígenas da TI Dourados passaram invariavelmente pelo Conselho Tutelar. A referência se justifica pelo temor de verem seus pequenos levados para fora da reserva. Esse tema também preocupa as lideranças e profissionais indígenas. A fala de um desses profissionais indígenas aponta a necessidade de um olhar mais sensível para as instituições e comportamentos indígenas. Segundo ele, o diálogo com o Conselho Tutelar só começou a melhorar depois que os indígenas passaram a assumir postos técnicos no CRAS. ${ }^{16}$

Então, o diálogo e a visão sobre a atuação dessas instituições começaram a mudar um pouco com a formação dos profissionais indígenas, que passaram a atuar nessa política de assistência social. Passaram a atuar como assistente social, como psicólogo, nos Centros de Referência de Assistência Social que existem em Dourados, que tem um CRAS Indígena. Um desafio que nós enfrentamos como indígenas, enquanto profissionais, atuantes na nossa comunidade, é a forma com que o Conselho Tutelar, que é um conselho não indígena (não existe um conselho tutelar indígena), aborda determinadas situações na comunidade.

A relação do CRAS com o Conselho Tutelar, a propósito, tem gerado dificuldades para muitas famílias indígenas. Para lidar com supostas situações de negligência com relação a incapazes (crianças) decorrentes do uso de álcool e drogas, os técnicos do CRAS comumente acionam o Conselho Tutelar, que vai até a reserva, retiram as crianças e levam para o Lar Santa Rita, na cidade de Dourados. Outras vezes, o Conselho recebe denúncias anônimas que têm o mesmo resultado: crianças extraídas arbitrariamente do seu contexto familiar e comunitário e levadas para fora da reserva (Nascimento,

${ }^{16}$ Kennedy Souza Moraes, formado em Serviço Social pela Universidade da Grande Dourados (Unigran), com mestrado em desenvolvimento sustentável (Centro de Desenvolvimento Sustentável da UnB), foi assistente social no CRAS Indígena Bororó. O trecho aqui apresentado é da entrevista registrada pelo antropólogo Spency Pimentel, em outubro de 2013, a quem agradeço a gentileza da concessão, com a devida autorização do entrevistado. Para a íntegra, consultar Borges (2015).

Horizontes Antropológicos, Porto Alegre, ano 22, n. 46, p. 303-328, jul./dez. 2016 
2013). Como salienta Pimentel (2014, p. 26), “diversas pessoas suspeitam de que denúncias mal-intencionadas sejam realizadas por evangélicos [indígenas, que são maioria na reserva], por conta do preconceito desse grupo contra as pessoas que consomem álcool - ainda que estas não tenham histórico de violência contra as crianças". Os agentes tutelares vêm retirando as crianças sem diálogo com a comunidade, o que "frequentemente resulta em injustiças por vezes dificilmente sanáveis como a adoção de crianças por famílias não indígenas" (Pimentel, 2014, p. 26). Sem desconsiderar que pode haver correlação entre alcoolismo dos pais e desnutrição infantil, as arbitrariedades do Conselho Tutelar, por certo, representam flagrante violação do direito à consulta prévia, estabelecido na Convenção n ${ }^{\circ} 169$ (OIT, 1989), e desconhecimento das formas locais de organização social.

É inegável que o CRAS Indígena de Dourados resulta do protagonismo indígena. A começar pela sua instalação, a primeira do gênero no país, tudo foi conquistado pela mobilização da comunidade através das lideranças. Também decorre da sua participação nas instâncias de deliberação local a ampliação do CRAS, que antes funcionava num pequeno prédio em formato de oca. Sua presença no território fez possível o acompanhamento das famílias indígenas de perto pelo Estado. Trouxe avanços no trabalho social: as famílias têm onde buscar informações, fazer documentos, participar de cursos e palestras, receber benefícios; é onde já acessam alguns direitos socioassistenciais hoje em dia. A demanda aumenta a cada dia pelos serviços e, diante disso, os índios já têm apresentado, nas últimas conferências municipais de assistência social, a reivindicação pela ampliação do número de funcionários, criação de outro CRAS (na aldeia Jaguapiru) e um CREAS (Centro de Referência Especial de Assistência Social) dentro da reserva. Quanto ao diálogo com o Conselho Tutelar, eu soube, através de Gaudêncio Benitez, que há cerca de um ano foi feito acordo - entre o Conselho Tutelar e os caciques - para que as crianças não sejam mais retiradas das famílias antes que as lideranças sejam comunicadas e tentem uma solução interna (Borges, 2015).

\section{Discussão teórica}

O caso de Dourados revela o quanto a assistência social ainda precisa avançar para se tornar uma política pública diferenciada. Sem dúvida, essa construção deve levar em conta as crenças, organização social e tradições 
indígenas, em estreita observância aos marcos legais constituídos. Para tanto, é imprescindível aprimorar os canais e as formas de comunicação intercultural entre o CRAS e indígenas. Estes esperam que as ações socioassistencias consigam enxergar as famílias extensas (e não apenas as famílias elementares, alvo dos programas de transferência de renda) e, como consequência, que seja estabelecido um Conselho Tutelar Indígena, baseado nas noções indígenas de política e justiça que se espraiam em sua organização social. A estatalidade da assistência deve, pois, traduzir as categorias operacionais dos serviços socioassistenciais de acordo com o universo sociocultural indígena.

Para os povos indígenas, os temas da autonomia e do protagonismo são particularmente caros. Trata-se de conceitos que devem ultrapassar os limites da família para alcançar a coletividade: a redação do objetivo central do PAIF anuncia que autonomia e protagonismo se referem a "famílias $e$ comunidades". O sentido político aqui se amplia quando relembramos que eles têm resguardado o direito coletivo à autodeterminação, tanto pela Constituição Federal quanto pela Convenção $n^{0} 169$ da Organização Internacional do Trabalho (OIT, 1989) e pela Declaração das Nações Unidas sobre os Direitos dos Povos Indígenas (Nações Unidas, 2008). Como observa Sánchez (2009, p. 66), os povos indígenas da América Latina têm optado por exercer a autodeterminação dentro dos países em que estão inseridos, o que desqualifica o temor ideológico de setores conservadores de que esse direito é uma ameaça à "soberania nacional”. A manutenção de suas formas próprias de vida sociocultural, no interior dos Estados nacionais, requer o exercício da autonomia, que implica

um sistema pelo qual os povos indígenas podem exercer seu direito à livre determinação sob o marco de seus respectivos Estados. Para ela [autonomia], são imprescindíveis o reconhecimento jurídico e político da existência dos povos indígenas e sua configuração em coletividades políticas, em um marco estatal baseado na diversidade sociocultural. (Sánchez, 2009, p. 69).

Sob regimes de autonomia, os povos indígenas teriam capacidades especiais de conduzir livremente seus modos de vida, exercer o controle de seus assuntos internos, gerenciar certas questões por si mesmos e gozar de um conjunto de direitos. Sendo assim, a autonomia dos povos indígenas significa: ter autoridades próprias para tomar decisões em determinadas esferas e exercer 
poderes para regrar a vida interna e administrar seus assuntos políticos, econômicos, administrativos, culturais, educacionais, ambientais e de saúde, sobre uma base territorial com limites reconhecidos, com total liberdade para participar da vida política regional e nacional. Do ponto de vista indígena, autonomia é o guia a seguir rumo à construção de sociedades mais justas e democráticas, uma vez que assegura o exercício concreto do direito à livre determinação.

A autonomia é uma política de identidade que busca articular as mudanças estruturais para perseguir a igualdade e a justiça com mudanças socioculturais para estabelecer o reconhecimento das diferenças e cancelar todo tipo de subordinação, exclusão ou discriminação dos grupos identitários. [...] O que se requer é definir uma política progressista de identidade que garanta a articulação das mudanças estruturais para alcançar a igualdade e a justiça com mudanças socioculturais para estabelecer o reconhecimento das diferenças e desterrar as desigualdades que minoram e desrespeitam os grupos identitários. (Díaz Polanco, 2005, p. 53, 61, tradução minha).

Igualdade e diferença são metas estratégias da autonomia e devem penetrar a formulação, execução e avaliação das políticas públicas para povos indígenas, a exemplo da assistência social. Política pública consiste em um conjunto de decisões sancionadas pelos agentes governamentais para solução de questões reconhecidas como problemáticas pela sociedade. No processo, são concebidas e executadas ações que têm caráter jurídico imperativo, estando sujeitas à influência de atores não estatais (Rua, 2009; Secchi, 2010). A superação do "colonialismo interno" (ver Cardoso de Oliveira, 1978) emanado das políticas públicas indigenistas requer a assunção dos indígenas como sujeitos plenamente capazes de conceber e executar políticas públicas de seu interesse, em contraposição à postura estatal de "guardião" dos índios, tidos como infantis, puros demais ou "relativamente incapazes" (Ramos, 1998; Verdum, 2006).

A noção de política pública aponta para três dimensões mutuamente relacionadas. A primeira dimensão é simbólica, conceitual, em que são socialmente construídos problemas, se explicitam demandas, se elaboram discursos públicos com base em valores, marcos de sentido e sistemas de crenças. A segunda dimensão é substantiva, ou seja, é o processo onde se tomam decisões e se formulam as políticas na forma de leis, programas e/ou ações; depende de 
negociações, acordos e decisões juridicamente embasadas. A última das três dimensões é operativa: é o processo de implementação da política já decidida, em que se põem em marcha os mecanismos de produção de serviços, programas e projetos governamentais. ${ }^{17}$

$\mathrm{Na}$ América Latina, conforme aponta Llancaqueo (2005, p. 77-78), os indígenas e suas organizações representativas têm conseguido influenciar a primeira das três dimensões: "direitos indígenas", "territórios", "autonomia", "diferenças", "diversidade cultural", dentre outros, são novos conceitos introduzidos na arena política para forçar Estados e sociedades nacionais a reconhecer problemáticas colocadas por esses novos sujeitos de direitos. É esse o momento da definição das agendas políticas em que ocorrem disputas com outros atores sociais estruturalmente mais fortes: "vai sendo formada por meio de diferentes mecanismos de pressão externa de grupos organizados em partidos políticos, sindicatos, associações patronais, na imprensa [...], por iniciativa interna do governo, pela burocracia pública, etc." (Jannuzzi, 2011, p. 261). Assim, embora nos últimos anos tenhamos testemunhado êxito na visibilidade de certos temas de interesse étnicos, o desempenho indígena nas outras dimensões (substantiva e operativa) é insuficiente, deixando espaço para que outros atores sociais, entranhados na máquina do Estado, desvirtuem, bloqueiem, posterguem ou anulem as políticas de direitos indígenas, seja na fase de definições ou na implementação.

É onde justamente o protagonismo indígena pode incidir. "Espera-se que o trabalho social do PAIF, ao promover aquisições sociais e materiais, possibilite às comunidades, famílias e seus membros o exercício da autonomia e do protagonismo - atributos inter-relacionados e essenciais na conquista de direitos e alcance da cidadania" (Brasil, 2012b, p. 54). Ou seja, o Serviço tem potencial para promover maior equidade nas relações interétnicas entre índios e brancos.

\footnotetext{
17 Nos manuais clássicos da ciência política, essas dimensões correspondem às etapas sucessivas do processo de formulação das políticas públicas: 1) definição da agenda política, em que se reconhece uma questão social como problema público e a consequente necessidade de ação governamental; 2) formulação de políticas e programas, quando então são concebidas soluções, encaminhamentos e programas de ações para lidar com o problema recém-legitimado; 3) tomada de decisões, em que se define, dentre as várias alternativas elencadas na fase anterior, a ação efetiva a seguir; 4) a implementação de programas e políticas corresponde aos esforços de efetivação da ação governamental na alocação de recursos e desenvolvimentos dos processos previstos; 5) por fim, a avaliação das políticas e programas permite a detecção de falhas e a correção de rumos visando aos objetivos propostos (ver Jannuzzi, 2011).
}

Horizontes Antropológicos, Porto Alegre, ano 22, n. 46, p. 303-328, jul./dez. 2016 


\section{Conclusão}

A condição de indígena - em si - não pode ser, e não é, sinônimo de vulnerabilidade. Como vimos no caso de Dourados, as situações que tornam famílias e coletivos indígenas vulneráveis e elegíveis a serviços, programas, projetos e benefícios da assistência social são produto do cerco colonial que perpassa o aparato estatal visando à reprodução do sistema capitalista, que cada vez mais cerca e penetra os territórios indígenas na sanha incessante de geração de mercadorias. Diante disso, é preciso superar a visão essencialista que, por um lado, é cega ao dinamismo das identidades étnicas e, por outro, ignora as bases socioeconômicas e políticas dos regimes de dominação cultural.

É nessa conjuntura histórica - marcada por contradições - que a assistência social se apresenta para esses sujeitos. Um contexto de ameaça aos direitos indígenas, que faz dos serviços socioassistenciais uma grande oportunidade vinda justamente do Estado.

\section{Referências}

ALVAREZ, G. O. "No soy mandado, soy jubilado": previsión social y pueblos indígenas en el Amazonas brasileño. In: SILVA, C. T.; LIMA, A. C. S.; BAINES, S. G. (Org.). Problemáticas sociais para sociedades plurais: políticas indigenistas, sociais e desenvolvimento em perspectiva comparada. São Paulo: Annablume; Brasília: FAP-DF, 2009. p. 159-184.

BAINES, S. G. Organizações indígenas e legislações indigenistas no Brasil, na Austrália e no Canadá. Brasília: DAN, 2001. (Série Antropologia, n. 295).

BORGES, J. C. Produto 4: documento técnico descritivo-analítico contendo a sistematização e análise das informações obtidas em campo: dados obtidos com as entrevistas dos técnicos das equipes, com as lideranças e famílias indígenas; relato sistemático da observação de campo, informações sobre os CRAS/ experiências de atuação das equipes visitadas e percepções, significados, críticas e sugestões dos indígenas a respeito dos serviços ofertados. Brasília: Ministério do Desenvolvimento Social e Combate à Fome, 2015. 
BRASIL. Lei $n^{\circ}$ 8.080, de 19 de setembro de 1990. Dispõe sobre as condições para a promoção, proteção e recuperação da saúde, a organização e o funcionamento dos serviços correspondentes e dá outras providências. Brasília, 1990. Disponível em: <http://www.planalto.gov.br/ccivil_03/leis/ L8080.htm>. Acesso em: 27 set. 2015.

BRASIL. Lei $n^{\circ} 8.742$, de 7 de setembro de 1993. Dispõe sobre a organização da Assistência Social e dá outras providências. Brasília, 1993. Disponível em: $<$ http://www.planalto.gov.br/ccivil_03/leis/L8742.htm>. Acesso em: 27 set. 2015.

BRASIL. Decreto $n^{\circ} 3.156$, de 27 de agosto de 1999. Dispõe sobre as condições para a prestação de assistência à saúde dos povos indígenas, no âmbito do Sistema Único de Saúde. Brasília, 1999a. Disponível em: <http:/www.planalto. gov.br/ccivil_03/decreto/D3156.htm>. Acesso em: 27 set. 2015.

BRASIL. Lei $n^{\circ}$ 9.836, de 23 de setembro de 1999. Acrescenta dispositivos à Lei n ${ }^{\circ} 8.080$, de 19 de setembro de 1990, que "dispõe sobre as condições para a promoção, proteção e recuperação da saúde, a organização e o funcionamento dos serviços correspondentes e dá outras providências", instituindo o Subsistema de Atenção à Saúde Indígena. Brasília, 1999b. Disponível em: <http://www. planalto.gov.br/ccivil_03/leis/19836.htm>. Acesso em: 27 set. 2015.

BRASIL. Ministério da Saúde. Portaria no 254, de 31 de janeiro de 2002. Diário Oficial da União, Brasília, 6 fev. 2002. Seção 1, p. 46-49.

BRASIL. Ministério do Desenvolvimento Social e Combate à Fome. Conselho Nacional de Assistência Social. Resolução $n^{\circ}$ 145, 15 de outubro de 2004. Aprova a Política Nacional de Assistência Social. Brasília, 2004. Disponível em: <https://www.legisweb.com.br/legislacao/?id=101000>. Acesso em: 27 set. 2015.

BRASIL. Ministério do Desenvolvimento Social e Combate à Fome. Secretaria Nacional de Assistência Social. NOB 1/2005 - Norma Operacional Básica do SUAS. Brasília, 2005. Disponível em: <http://www.ppd.mppr.mp.br/modules/ conteudo/conteudo.php?conteudo=26>. Acesso em: 27 set. 2015. 
BRASIL. Ministério do Desenvolvimento Social e Combate à Fome. Conselho Nacional de Assistência Social. Resolução $n^{\circ}$ 47, de 22 de março de 2006. Institui Grupo de Trabalho para acompanhar gestão dos recursos da Rede Serviços de Proteção Social Básica - Quilombolas. Brasília, 2006. Disponível em: $\quad<$ http://www.mds.gov.br/cnas/legislacao/resolucoes/arquivos-2006/ CNAS 2006 - 047 - 22.03.2006.doc/download>. Acesso em: 27 set. 2015.

BRASIL. Ministério do Desenvolvimento Social e Combate à Fome. Conselho Nacional de Assistência Social. Relatório GT Povos Indígenas. Brasília, mar. 2007a.

BRASIL. Ministério da Saúde. Portaria $n^{\circ}$ 2.656, de 17 de outubro de 2007. Dispõe sobre as responsabilidades na prestação da atenção à saúde dos povos indígenas, no Ministério da Saúde e regulamentação dos Incentivos de Atenção Básica e Especializada aos Povos Indígenas. Brasília, 2007b. Disponível em: $<$ http://bvsms.saude.gov.br/bvs/saudelegis/gm/2007/prt2656_17_10_2007. html>. Acesso em 27 set. 2015.

BRASIL. Ministério da Saúde. Portaria $n^{\circ} 2.760$, de 18 de novembro de 2008. Altera a redação do art. 20 da Portaria n ${ }^{\circ}$ 2.656/GM, de 17 de outubro de 2007. Brasília, 2008. Disponível em: <http://bvsms.saude.gov.br/bvs/saudelegis/ gm/2008/prt2760_18_11_2008.html>. Acesso em: 27 set. 2015.

BRASIL. Ministério da Saúde. Portaria $n^{\circ} 116$, de 11 de fevereiro de 2009. Regulamenta a coleta de dados, fluxo e periodicidade de envio das informações sobre óbitos e nascidos vivos para os Sistemas de Informações em Saúde sob gestão da Secretaria de Vigilância em Saúde. Brasília, 2009. Disponível em: $<$ http://bvsms.saude.gov.br/bvs/saudelegis/svs/2009/prt0116_11_02_2009. html>. Acesso em: 27 set. 2015.

BRASIL. Decreto $n^{\circ} 7.336$, de 19 de outubro de 2010. Aprova a Estrutura Regimental e o Quadro Demonstrativo dos Cargos em Comissão e das Funções Gratificadas do Ministério da Saúde, e dá outras providências. (Revogado pelo Decreto $n^{\circ}$ 7.530/2011). Brasília, 2010a. Disponível em: $<$ http://www.planalto.gov.br/ccivil_03/_Ato2007-2010/2010/Decreto/D7336. htm>. Acesso em: 27 set. 2015. 
BRASIL. Ministério do Trabalho e Previdência Social. Instituto Nacional do Seguro Social. Instrução Normativa INSS/PRES n ${ }^{\circ} 45$, de 6 de agosto de 2010. Dispõe sobre a administração de informações dos segurados, o reconhecimento, a manutenção e a revisão de direitos dos beneficiários da Previdência Social e disciplina o processo administrativo previdenciário no âmbito do Instituto Nacional do Seguro Social - INSS. Brasília, 2010b. Disponível em: $<$ http:// www.normaslegais.com.br/legislacao/instrucaonormativainss45_2010.htm>. Acesso em: 27 set. 2015.

BRASIL. Lei $n^{\circ} 12.435$, de 6 de julho de 2011. Altera a Lei no 8.742, de 7 de dezembro de 1993, que dispõe sobre a organização da Assistência Social. Brasília, 2011. Disponível em: <http://www.planalto.gov.br/ccivil_03/ ato2011-2014/2011/lei/112435.htm>. Acesso em: 27 set. 2015.

BRASIL. Ministério do Desenvolvimento Social e Combate à Fome. Conselho Nacional de Assistência Social. Resolução n 33, em 12 de dezembro de 2012. Aprova a NOB/SUAS. Brasília, 2012a. Disponível em: <http://www.mds.gov. br/cnas/legislacao/resolucoes/arquivos-2012/cnas-2012-033-12-12-2012.pdf/ download $>$. Acesso em: 27 set. 2015.

BRASIL. Ministério do Desenvolvimento Social e Combate à Fome. Secretaria Nacional de Assistência Social. Orientações técnicas sobre o PAIF, vol. 1: o Serviço de Proteção e Atendimento Integral à Família - PAIF, segundo a Tipificação Nacional de Serviços Socioassistenciais. Brasília, 2012b.

CARDOSO DE OLIVEIRA, R. Identidade, etnia e estrutura social. São Paulo: Pioneira, 1978.

CARNEIRO DA CUNHA, M. Índios no Brasil: história, direitos e cidadania. São Paulo: Claro Enigma, 2012.

CASTILHO, E. W. Direitos humanos das populações indígenas. Revista Direitos Humanos, Brasília: Secretaria Especial de Direitos Humanos/ Presidência da República, n. 3, p. 19-22, set. 2009.

CLASTRES, P. Troca e poder: filosofia da chefia indígena. In: CLASTRES, P. A sociedade contra o Estado. Rio de Janeiro: Francisco Alves, 1990. p. 21-35. 
COLIN, D.; JACCOUD, L. Assistência social e construção do SUAS balanços e perspectivas: o percurso da Assistência Social como política de direitos e a trajetória necessária. In: COLIN, D. et al. (Org.). 20 anos da Lei Orgânica da Assistência Social. Brasília: MDS, 2013. p. 42-65.

DÍAZ POLANCO, H. Los dilemas del pluralismo. In: DÁVALOS, P. (Org.). Pueblos indígenas, Estado y democracia. Buenos Aires: CLACSO, 2005. p. 43-66.

DIEHL, E. E.; LAGNDON, E. J.; DIAS-SCOPEL, R. P. Contribuição dos agentes indígenas de saúde na atenção diferenciada à saúde dos povos indígenas brasileiros. Cadernos de Saúde Pública, Rio de Janeiro, v. 28, n. 5, p. 819-831, maio 2012.

DOURADOS. Lei Municipal $n^{\circ} 3.783$, de 23 de abril de 2014. Publicada no Diário Oficial de Dourados no dia 28 de abril de 2014, dispõe sobre o Sistema Municipal de Assistência Social. Dourados, 2014. Disponível em: $<$ http://www. dourados.ms.gov.br/index.php/lei-no-3783-dispoe-sobre-o-sistema-municipalde-assistencia-social-de-dourados-suas/?print=print>. Acesso em: 27 set. 2015.

FOUCAULT, M. Vigiar e punir: o nascimento das prisões. Rio de Janeiro: Vozes, 2002.

GOMES, M. P. Os índios e o Brasil. Petrópolis: Vozes, 1991.

IBGE. Censo Demográfico 2010: características gerais dos indígenas. Resultados do universo. Rio de Janeiro, 2012.

JANNUZZI, P. de M. Avaliação de políticas sociais no Brasil: repensando práticas e metodologias de pesquisas avaliativas. Planejamento e Políticas Públicas, Brasília, n. 36, p. 251-275, jan./jun. 2011. Disponível em: $<$ http://www.ipea.gov. br/ppp/index.php/PPP/article/viewFile/228/212>. Acesso em: 23 jun. 2014.

LIMA, A. C. S. Um grande cerco de paz: poder tutelar, indianidade e formação do Estado no Brasil. Petrópolis: Vozes, 1995.

LLANCAQUEO, V. T. Políticas indígenas y derechos territoriales en América Latina: 1990-2004. In: DÁVALOS, P. (Org.). Pueblos indígenas, Estado y democracia. Buenos Aires: CLACSO, 2005. p. 67-102. 
MARSTON, S. Space, culture, state: uneven developments in political geography. Political Geography, Tucson, n. 23, p. 1-16, 2004.

NAÇÕES UNIDAS. Declaração das Nações Unidas sobre os direitos dos povos indígenas. Rio de Janeiro, 2008. Disponível em: $<$ http://www.un.org/ esa/socdev/unpfii/documents/DRIPS_pt.pdf $>$. Acesso em: 20 set. 2015.

NASCIMENTO, S. Crianças indígenas kaiowá abrigadas e em situação de reinserção familiar: uma análise em torno da rede de proteção à criança $\mathrm{e}$ ao adolescente. 2013. Dissertação (Mestrado em Antropologia)-Faculdade de Ciências Humanas, Universidade Federal da Grande Dourados, Dourados, 2013.

NOVO, M. P. Os agentes indígenas de saúde do Alto Xingu. Brasília: Paralelo $15,2010$.

OIT. Convenção $n^{\circ}$ 169. Genebra, 1989. Disponível em: <http://www.oit.org. br/node/513>. Acesso em: 20 set. 2015.

PIMENTEL, S. K. Produto 3: documento apresentado à Secretaria de Avaliação e Gestão da Informação, do Ministério do Desenvolvimento Social e Combate à Fome, no âmbito do contrato no SA- 2329/2013 referente ao Projeto 914BRZ3002. Brasília: SAGI/MDS, jan. 2014.

QUIJANO, A. El "movimiento indígena" e las cuestiones pendientes en América Latina. In: QUIJANO, A. Cuestiones y horizontes: de la dependencia histórico-estrutural a la colonialidad/descolonialidad del poder. Buenos Aires: CLACSO, 2014. p. 635-666.

RAMOS, A. R. Indigenism: ethnic politics in Brazil. Madison: The University of Winconsin Press, 1998.

RAMOS, A. R. The predicament of Brazil's pluralism. Brasília: DAN, 2001. (Série Antropologia, n. 303).

RIBEIRO, D. Os índios e a civilização: a integração das populações indígenas no Brasil moderno. São Paulo: Companhia das Letras, 1996. 
ROCA, J. L. Estatalidade: entre la pugna regional y el institucionalismo. Cuaderno de Futuro, n. 21. Informe sobre Desarrollo Humano. La Paz: IDH/ PNUD Bolívia, nov. 2005.

RUA, M. das G. Políticas públicas. Florianópolis: Departamento de Ciências da Administração/UFSC, 2009.

SÁNCHEZ, C. Autonomia, Estados pluriétnicos e plurinacionais. In: VERDUM, R. (Org.). Povos indígenas: constituições e reformas políticas na América Latina. Brasília: INESC, 2009. p. 63-90.

SANTOS, R. V.; COIMBRA Jr., C. E. A. Cenários e tendências da saúde e da epidemiologia dos povos indígenas no Brasil. In: COIMBRA Jr., C. E. A.; SANTOS, R. V.; ESCOBAR, A. L. Epidemiologia e saúde dos povos indígenas do Brasil. Rio de Janeiro: Fiocruz: Abrasco, 2003. p. 13-47.

SECCHI, L. Políticas públicas: conceitos, esquemas de análise, casos práticos. São Paulo: Cengage Learning, 2010.

SILVA, C. D. Cotidiano, saúde e política - uma etnografia dos profissionais da saúde indígena. 2010. Tese (Doutorado em Antropologia Social)-Instituto de Ciências Sociais, Universidade de Brasília, Brasília, 2010.

SPOSATI, A. Os 20 anos da LOAS: a ruptura com o modelo assistencialista. In: COLIN, D. et al. (Org.). 20 anos da Lei Orgânica da Assistência Social. Brasília: MDS, 2013. p. 20-41.

VERDUM, R. Etnodesenvolvimentismo: nova/velha utopia. 2006. Tese (Doutorado em Aantropologia Social)-Instituto de Ciências Sociais, Universidade de Brasília, Brasília, 2006.

VIVEIROS DE CASTRO, E. Histórias indígenas. Novos Estudos CEBRAP, São Paulo, n. 36, p. 22-33, jul. 1993.

ZAVALETA MERCADO, R. La autodeterminación de las masas. Bogotá: Clacso, 2009. 